\title{
Correction: Journal of Aerosol Medicine and Pulmonary Drug Delivery: 2015; 28/6:474-485
}

N THE ARTICLE "The ELLIPTA ${ }^{\circledR}$ Dry Powder Inhaler: Design, Functionality, In Vitro Dosing Performance and Critical Task Compliance by Patients and Caregivers" (published in the December, 2015 issue of Journal of Aerosol Medicine and Pulmonary Drug Delivery: 2015; 28/6:474-485) by Andrew C. Grant et al., the graph portions of Figures 6 and 7 were inadvertently switched. The graph of Fig. 6 on pg. 479 belongs on pg. 481 and the graph of Fig. 7 on pg. 481 belongs in pg. 479.

In addition, in column 2 on pg. 480 the data in the 7th line up from the bottom of the column should read $24.8 \%-42.8 \%$ rather than $24.8 \%-2.8 \%$.

The online version of the published article has been corrected.

The authors regret these errors. 